\title{
Depression and its Associated Factors among Patients with Chronic Obstructive Pulmonary Disease in Karachi, Pakistan
}

\author{
Gulshan Himani ${ }^{1}$, Abida Badini ${ }^{1}$, Kashmira Nanji ${ }^{2}$ \\ 1. Family Medicine, The Aga Khan University, Karachi, PAK 2. Epidemiology and Public Health, The Aga \\ Khan University, Karachi, PAK
}

$\square$ Corresponding author: Kashmira Nanji, kashmira.nanji@gmail.com Disclosures can be found in Additional Information at the end of the article

\section{Abstract}

\section{Introduction}

Depression in patients with chronic obstructive pulmonary disease (COPD) can be an incapacitating health problem that negatively affects the quality of life. If the depression is not treated, it is associated with increased morbidity and mortality. The goal of this study was to determine the frequency of depression in patients with COPD and examine the factors contributing to depression in these patients.

\section{Methods}

This cross-sectional study was conducted using a sample of 556 patients with COPD visiting the Pulmonology Clinic of the Aga Khan University Hospital in Karachi, Pakistan, from March 2010 to March 2011. A pretested structured questionnaire was used for data collection. The Hospital Anxiety and Depression Scale (HADS) was used to screen for depression. SPSS Statistics for Windows, Version 19.0. (IBM Corp, Armonk, NY) was used to enter and analyze data.

\section{Results}

Out of the total 556 participants, majority $62.9 \%$ were between 60 and 79 years of age and $70.1 \%$ of the participants were males. The frequency of depression in COPD patients was $57.2 \%$, and multiple logistic regression analyses indicated being over 59 years (Adjusted odds ratio (ORadj), 2.750; 95\% confidence interval [CI]: 1.25 to 6.05, $\mathrm{p}=0.039$ ), being male (ORadj, 2.28; 95\% CI: 0.89 to 5.14 ), being retired or unemployed (ORadj, $1.041 ; 95 \% \mathrm{CI}: 0.41$ to $2.62, \mathrm{p}=$ 0.000), using inhaled steroids (ORadj, 3.929; 95\% CI: 2.59 to 5.97, $\mathrm{p}=0.000$ ), and living alone were significantly associated with depression in COPD patients.

Received 06/07/2018 Review began 06/09/2018 Review ended 07/01/2018 Published 07/05/2018

\section{(c) Copyright 2018}

Himani et al. This is an open access article distributed under the terms of the Creative Commons Attribution License CC-BY 3.0., which permits unrestricted use, distribution, and reproduction in any medium, provided the original author and source are credited.

\section{Conclusion}

Several risk factors for depression in patients with COPD were identified. Patients with COPD who are elderly, male, retired or unemployed, use inhaled steroids, and patients who live alone have characteristics significantly associated with depression. These factors should be considered by practicing family physicians, pulmonologists, and healthcare workers.

Categories: Internal Medicine, Pulmonology, Public Health

Keywords: copd, depression, risk factors, hads, pakistan 


\section{Introduction}

Depression affects people all over the world [1]. Patients with chronic diseases in general and those with chronic obstructive pulmonary disease (COPD) in particular are likely to have coexisting depression compared with healthy individuals. There is a higher incidence of depression in patients with more severe COPD. In Pakistan, the frequency of depression in COPD patients has been reported as $15 \%$ and $72 \%$ in two different studies, while in China, a neighboring country, the frequency of depression was reported to be $35.7 \%[2-4]$.

Depression is also associated with frequent hospital readmission for acute exacerbation and is an independent prognostic factor for mortality in such patients [5,6]. Functional impairments associated with COPD are themselves potential promoters of depressive morbidity and chronicity [7,8]. Previous studies identified many factors associated with depression in COPD patients such as age, gender, employment status, living alone, and use of steroids [9-11].

Diagnosis of depression in patients with COPD is important, as early intervention to manage depression may improve patient's quality of life and decrease the cost of management. This study aimed to estimate the frequency and risk factors of depression among patients with COPD.

\section{Materials And Methods}

This cross-sectional study was conducted on 556 COPD patients aged 40 or above, who were consecutively recruited from the Pulmonology Clinic of the Aga Khan University in Karachi, Pakistan, from March 2010 to March 2011. Patients with preexisting depression, those with a recent death (within six months) of a spouse, sibling, parent or a child, and those on oral steroids were excluded from the study.

After obtaining written informed consent, a structured pretested questionnaire was administered for data collection. The questionnaire was composed of two sections. The first section included the demographic information of the participants, and the second part included the Hospital Anxiety and Depression Scale (HADS) to screen for depression. HADS is a validated screening tool with a sensitivity of $70 \%$ and a specificity of $90 \%$ [12]. The score ranges from zero to 21 for each subscale. Those COPD patients with scores eight or higher were labeled as having depression [12].

Descriptive, univariate, and multivariate logistic regression analyses were performed using SPSS Statistics for Windows, Version 19.0. (IBM Corp, Armonk, NY). Univariate analysis was carried out using simple logistic regression to evaluate each variable for its unadjusted association with depression by computing unadjusted odds ratios (ORs) and their 95\% confidence intervals (CI). Multivariable analysis was done using multiple logistic regressions to identify factors associated with depression and was reported as adjusted odds ratio (ORadj) and their $95 \%$ confidence intervals. $p<0.05$ was considered statistically significant throughout the analysis.

\section{Results}

A total of 556 of 650 patients consented to participate in the study resulting in a response rate of $85 \%$. The demographic details of the study population are presented in Table 1 . Fifty-seven percent of the patients with COPD who participated in the study were depressed. 


\section{Cureus}

Age

$\begin{array}{ll}40-59 \text { Years } & 151\end{array}$

27.2

60-79 Years

$>80$ Years

Gender

Male

Female

Educational status

Not educated

Primary

69

12.4

Secondary

109

19.6

Intermediate

148

26.6

Higher

189

34.0

Employment status

Employed

Retired

264

47.5

Housekeeper

Living alone

Yes

No

528

95

Marital status

Married

550

98.9

Unmarried

6

1.1

Household income

$<10,000$ PKR

10,000-50,000 PKR

$>50,000$ PKR

Body mass index $\left(\mathrm{kg} / \mathrm{m}^{2}\right)$

$<23$

$>23$

Steroid use $>3$ weeks
247

44.4

309
55.6 


\section{Cureus}

Yes

No

Smoking status

Daily

Occasional

Ex-smoker

Never

Never smoked

Smoking $<10$ cigarettes/day

Smoking >10 cigarettes/day

Depression

Yes

No
Current smoking

TABLE 1: Baseline characteristics of the study participants $(n=556)$.

Table 2 depicts the factors associated with depression among COPD patients. After adjusting for other variables in the final logistic regression model, patients older than 59 years (ORadj, 2.750; 95\% CI: 1.25 to 6.05), male (ORadj, 2.28; 95\% CI: 0.89 to 5.14), retired or unemployed (ORadj, 1.041; 95\% CI: 0.41 to 2.62), using inhaled steroids (ORadj, 3.929; 95\% CI: 2.59 to 5.97), and currently smoking (ORadj, 3.029; 95\% CI: 1.55 to 5.90) were factors significantly associated with depression in patients with COPD. People living alone had an increased risk (ORadj, 2.830; 95\% CI: 0.92 to 8.73 ) of having depression.

\section{Depression}

Variables

Yes $\quad \mathrm{No}$

Unadjusted OR (95\% Cl)

Adjusted OR (95\% Cl)

p value

$\mathrm{n} \quad \% \quad \mathrm{n} \quad \%$

Age

40-59 Years

$\begin{array}{lllll}64 & 20.1 & 87 & 36.6 & 1\end{array}$

60-79 Years

$208 \quad 65.4 \quad 142 \quad 59.7 \quad 6.948(3.17-15.21)$

$2.329(0.95-5.71)$

$0.039 *$

$>80$ Years

46

14.59

3.8

$3.489(1.65-7.35)$

$2.750(1.25-6.05)$

Gender

Male 


\section{Cureus}

Female

$80 \quad 25.2 \quad 86 \quad 36.1 \quad 1.683(1.16-2.42)$

$2.13(0.88-5.14)$

0.091

Educational status

Not educated

$\begin{array}{lllll}18 & 5.7 & 23 & 9.7 & 1\end{array}$

Primary

$\begin{array}{lllll}40 & 12.6 & 29 & 12.4 & 1.942 \\ (0.98-3.84)\end{array}$

Secondary

$\begin{array}{lllll}69 & 21.7 & 40 & 16.8 & 1.102(0.63-1.92)\end{array}$

NS

Intermediate

$\begin{array}{lllll}77 & 24.2 & 71 & 29.8 & 0.881 \\ (0.54-1.43)\end{array}$

Higher

$\begin{array}{lllll}114 & 35.8 & 75 & 31.5 & 1.402\end{array}(0.90-2.16)$

Employment status

Employed

Retired

Housekeeper

Living alone

Yes

No

Marital status

Married

Unmarried

Household income

$<10,000$ PKR

10,000-50,000 PKR

$>50,000$ PKR

Body mass index $\left(\mathrm{kg} / \mathrm{m}^{2}\right)$

$<23$

$>23$

Steroid use $>3$ weeks

Yes

No

$\begin{array}{lllll}260 & 81.8 & 114 & 47.9 & 1\end{array}$

$\begin{array}{lllll}58 & 18.2 & 124 & 52.1 & 4.876(3.32-7.14)\end{array}$

Current smoking

Never smoked

Smoking $<10$ cigarettes/day

$231 \quad 72.6 \quad 184 \quad 77.3 \quad 1$

$\begin{array}{lllll}52 & 16.4 & 22 & 9.2 \quad 1.88 & (1.32-2.02)\end{array}$ $\begin{array}{lllll}55 & 17.3 & 94 & 39.5 & 1\end{array}$

$\begin{array}{lllll}197 & 61.9 & 67 & 28.2 & 1.465\end{array}(0.91-2.33)$

$\begin{array}{lllll}66 & 20.8 & 77 & 32.4 & 0.292 \\ (0.19-0.44)\end{array}$

$\begin{array}{lllll}24 & 7.5 & 4 & 1.7 & 1\end{array}$

$294 \quad 92.5 \quad 234 \quad 98.3 \quad 4.776(1.63-13.95)$

$\begin{array}{lllll}313 & 98.4 & 237 & 99.6 & 1\end{array}$

$\begin{array}{lllll}5 & 1.6 & 1 & 0.4 & 3.786(0.43-32.62)\end{array}$

$\begin{array}{lllll}46 & 14.5 & 40 & 16.8 & 1\end{array}$

$172 \quad 54.1 \quad 130 \quad 54.6 \quad 1.279(0.75-2.15)$

NS

$\begin{array}{lllll}100 & 31.4 \quad 68 & 28.6 & 1.111(0.75-1.63)\end{array}$

$\begin{array}{lllll}163 & 51.3 & 84 & 35.3 & 1\end{array}$

$155 \quad 48.7 \quad 154 \quad 64.7 \quad 1.928(1.36-2.72)$

NS

NS

1

0.070

$0.225(0.12-0.40) \quad 0.000^{*}$

$1.041(0.41-2.61)$

$2.830(0.91-8.73)$

$3.929(2.58-5.96)$

1 


\section{Cureus}

TABLE 2: Factors associated with depression among COPD patients $(n=556)$.

COPD: Chronic obstructive pulmonary disease; Cl: Confidence interval; OR: Odds ratio; NS: Not significant; $p>0.05$.

\section{Discussion}

In this study, $57.2 \%$ of patients with COPD also had depression. Two studies conducted in Pakistan reported the frequency of depression in patients with COPD to be $15 \%$ and $72 \%$. The reason for this difference could be due to the small sample sizes used in those studies as compared to ours. Those studies also used different screening tools and were unable to control for confounding factors $[2,3]$.

A case-control study conducted on Chinese patients with and without COPD reported that the prevalence of depression is $35.7 \%$ in patients with COPD compared to $7.2 \%$ in patients without COPD [4]. In India, 33.3\% of patients with COPD showed moderate to severe depression, whereas $20.6 \%$ of patients had major depressive disorder [13]. The prevalence of depression in patients with COPD varies depending upon the country, study settings, and screening tools used.

Some studies state clinically significant levels of depression in patients with COPD were more prevalent in patients under age $60[4,8,14]$. This contrasts with our findings; we noted that patients with COPD over age 59 were more likely to have depression compared to patients aged 59 and younger. Depression in elderly COPD patients may reduce independence, resulting in a growing dependence on medical care. Similar findings have also been reported [15].

Smokers with COPD were more likely to have depressive symptoms in our study, which is a similar finding in many other studies $[8,16,17]$.

Several studies reported gender is an insignificant determinant of depression in patients with COPD, others concluded the female gender has a significant association with depression in these patients $[4,8,14,16]$. In contrast, our results showed male patients were more likely to suffer from depression. This may be due to a different study population in Pakistan where men are usually the family's main provider, and a chronic illness like COPD might cause a reduced ability to work, creating increased stress levels which can lead to depression. Further studies are needed to explore the association of the male gender and depression among patients with COPD.

We found that unemployment was directly associated with depression. Patients with COPD aged over 59 years were more likely to suffer from depression, and most of the patients over 59 years in our study were retired. A Turkish study also found similar results [9]. Living with the financial difficulties puts the retired COPD patients at a great social disadvantage and causes mental stresses and worries which then contributes toward the development of depression.

In our study, patients with COPD who lived alone were found to be at a higher risk of depression than those who have strong family support. These findings are consistent with a similar study conducted by Gudmundsson et al. on COPD and depression [10]. A possible explanation for this association of living alone and depression could be that patients living alone have fewer caregivers to provide physical and emotional support; this lack of support can contribute to depression. Interventions should be included to identify and strengthen the social networks of 
patients with COPD.

COPD patients on long-term steroid use reported a higher level of depression than those who were not receiving steroids. Gift et al. also found a strong association between depression in patients with COPD and steroid use [11]. Further studies are warranted to explore this relationship so that patients with COPD who also require steroid treatment can be monitored and treated accordingly.

Our study was limited in that participants of our study may not be representative of the general population; participants were subjects who attended a tertiary care hospital and may have different characteristics and severity levels than the general population. Moreover, this was a cross-sectional study, so temporality is difficult to establish, i.e., cause and effect relation between the factors and the disease (COPD).

Moreover, further studies are needed to determine the prevalence of depression in patients with COPD and to further investigate its causative factors in our society.

\section{Conclusions}

Our findings indicate a need to focus on depressive symptoms and risk factors associated with depression among patients with COPD. Families and communities should be made aware of depressive symptoms and its associated risk factors so that patients can be screened earlier. Clinicians can support positive mental health outcomes through the early identification of patients with COPD who may be at risk for psychological distress. Clinicians could refer these patients for individual or group counseling in an effort to improve outcomes and quality of life for these patients.

\section{Additional Information \\ Disclosures}

Human subjects: Consent was obtained by all participants in this study. Animal subjects: All authors have confirmed that this study did not involve animal subjects or tissue. Conflicts of interest: In compliance with the ICMJE uniform disclosure form, all authors declare the following: Payment/services info: All authors have declared that no financial support was received from any organization for the submitted work. Financial relationships: All authors have declared that they have no financial relationships at present or within the previous three years with any organizations that might have an interest in the submitted work. Other relationships: All authors have declared that there are no other relationships or activities that could appear to have influenced the submitted work.

\section{References}

1. World Health Organization depression fact sheet. (2018). Accessed: April 9, 2018 : http://www.who.int/entity/mediacentre/factsheets/fs369/en.

2. Motiani B, Haidri FR, Rizvi N: Frequency of depression in chronic obstructive pulmonary disease (COPD) patients. Pak J Med Sci. 2011, 27:1112-1115.

3. Phulpoto JA, Mohammad S: Frequency of depression in stable chronic obstructive pulmonary disease patients attending Ghulam Mohammad Mahar Medical College Hospital, Sukkur, Pakistan. Rawal Med J. 2012, 37:352-355.

4. Lou P, Zhu Y, Chen P, et al.: Prevalence and correlations with depression, anxiety, and other features in outpatients with chronic obstructive pulmonary disease in China: a cross-sectional case control study. BMC Pulm Med. 2012, 12:53. 10.1186/1471-2466-12-53

5. Xu W, Collet JP, Shapiro S, et al.: Independent effect of depression and anxiety on chronic obstructive pulmonary disease exacerbations and hospitalizations. Am J Respir Crit Care Med. 
2008, 178:913-920. 10.1164/rccm.200804-6190C

6. Qian J, Simoni-Wastila L, Rattinger GB, et al.: Associations of depression diagnosis and antidepressant treatment with mortality among young and disabled Medicare beneficiaries with COPD. Gen Hosp Psychiatry. 2013, 35:612-618. 10.1016/j.genhosppsych.2013.06.005

7. Hill K, Geist R, Goldstein RS, Lacasse Y: Anxiety and depression in end-stage COPD . Eur Respir J. 2008, 31:667-677. 10.1183/09031936.00125707

8. Hanania NA, Müllerova H, Locantore NW, et al.: Determinants of depression in the ECLIPSE chronic obstructive pulmonary disease cohort. Am J Respir Crit Care Med. 2011, 183:604-611. 10.1164/rccm.201003-04720C

9. Ünsal A, Ünaldi C, Baytemir Ç: Anxiety and depression levels of inpatients in the city centre of Kirşehir in Turkey. Int J Nurs Pract. 2011, 17:411-418. 10.1111/j.1440-172X.2011.01949.x

10. Gudmundsson G, Gislason T, Janson C, et al.: Depression, anxiety and health status after hospitalisation for COPD: a multicentre study in the Nordic countries. Respir Med. 2006, 100:87-93. 10.1016/j.rmed.2005.04.003

11. Gift AG, Wood RM, Cahill CA: Depression, somatization and steroid use in chronic obstructive pulmonary disease. Int J Nurs Stud. 1989, 26:281-286. 10.1016/00207489(89)90009-6

12. Bjelland I, Dahl AA, Haug TT, Neckelmann D: The validity of the Hospital Anxiety and Depression Scale: an updated literature review. J Psychosom Res. 2002, 52:69-77. 10.1016/S0022-3999(01)00296-3

13. Negi H, Sarkar M, Raval AD, Pandey K, Das P: Presence of depression and its risk factors in patients with chronic obstructive pulmonary disease. Indian J Med Res. 2014, 139:402-408.

14. Hynninen MJ, Bjerke N, Pallesen S, Bakke PS, Nordhus IH: A randomized controlled trial of cognitive behavioral therapy for anxiety and depression in COPD. Respir Med. 2010, 104:986994. 10.1016/j.rmed.2010.02.020

15. Kowalczyk-Sroka B, Marmurowska-Michalowska H: The level of anxiety and depression in the opinion of patients hospitalized due to chronic obstructive pulmonary disease (Article in Polish). Psychiatr Pol. 2005, 39:41-49.

16. Aryal S, Diaz-Guzman E, Mannino DM: COPD and gender differences: an update . Transl Res. 2013, 162:208-218. 10.1016/j.trsl.2013.04.003

17. Coultas DB, Edwards DW, Barnett B, Wludyka P: Predictors of depressive symptoms in patients with COPD and health impact. COPD. 2007, 4:23-28. 10.1080/15412550601169190 